\title{
Sistema de avisos meteorológicos del Departamento de Seguridad del Gobierno Vasco orientado a impactos
}

https://doi.org/10.31978/639-19-010-0.719

\author{
José Antonio Aranda Eguia ${ }^{1}$ (Resp-Meteo@euskadi.eus) \\ Pedro Anitua Aldekoa ${ }^{1}$ (panitua@seg.euskadi.eus)
}

${ }^{1}$ Gobierno Vasco / Dirección de Atención de Emergencias y Meteorología

\begin{abstract}
RESUMEN
El sistema de avisos, alertas y alarmas meteorológicas del Departamento de Seguridad del Gobierno Vasco se basa en el concepto «impacto esperable» en vez de en el concepto «umbral meteorológico». La predicción del impacto que se producirá en la sociedad por un futuro fenómeno meteorológico adverso es una segunda derivada predictiva, ya que la primera derivada es la propia predicción meteorológica, lo que dificulta su generación. Sin embargo, la sociedad exige saber cómo le va a influir un determinado fenómeno meteorológico adverso y es obligación de las instituciones competentes adecuar el sistema para que la ciudadanía tome las medidas de autoprotección más adecuadas.

Por ello, el Gobierno Vasco, de conformidad con lo establecido en la Ley de Gestión de Emergencias (autonómica), ha adecuado el sistema de avisos meteorológicos europeo EMMA a un sistema en el que los colores semafóricos van asociados al concepto AVISO, ALERTA Y ALARMA, distinguiendo entre «normalidad», «falta de normalidad»y «excepcionalidad», todos ellos orientados a IMPACTO. Esto significa que una misma situación meteorológica, una misma predicción meteorológica en función de época del año, hora del día, actividades programadas, estado del suelo... pueden generar distintos niveles de problemáticas y, por ende, distintos impactos en la población, y por tanto, distinta semaforización.

Esta filosofía unida a una vigilancia intensiva, a un sistema de comunicación a la población y a las instituciones rápido y abierto y a una rápida intervención de los sistemas de emergencia provoca una alta efectividad y un gran ahorro en daños.
\end{abstract}

PALABRAS CLAVE: emergencias; impactos meteorológicos; aviso amarillo; alerta naranja; alarma roja. 
